\title{
Combining OSMAC, Metabolomic and Genomic Methods on Termite Symbiotic Fungi for the Production and Annotation of Halogenated Azaphilones and Ilicicolins
}

\section{Téo Hebra}

Université Paris-Saclay, CNRS, Institut de Chimie des Substances Naturelles

Nicolas Pollet

Université Paris-Saclay, CNRS, IRD, EGCE

David Touboul

Université Paris-Saclay, CNRS, Institut de Chimie des Substances Naturelles

Véronique Eparvier ( $\nabla$ veronique.eparvier@cnrs.fr)

Université Paris-Saclay, CNRS, Institut de Chimie des Substances Naturelles

\section{Research Article}

Keywords:

Posted Date: January 31st, 2022

DOI: https://doi.org/10.21203/rs.3.rs-1258047/v1

License: (c) (1) This work is licensed under a Creative Commons Attribution 4.0 International License.

Read Full License 


\section{Abstract}

We mined a collection of termite mutualistic strains from French Guiana to explore metabolites of symbiotic microorganisms. Molecular networks reconstructed from a metabolomic analysis using LC-ESIMS/MS methodology led us to identify two families of chlorinated polyketides, i.e. azaphilones from Penicillium sclerotiorum and ilicolins from Neonectria discophora. To define the biosynthetic pathways related to these two types of scaffolds, we used a whole genome sequencing approach followed by hybrid assembly from short and long reads. We found two biosynthetic gene clusters including two FADdependent halogenases. To exploit the enzymatic promiscuity of the two identified FAD halogenases, we sought to biosynthesize novel halogenated metabolites. An OSMAC strategy was used and resulted in the production of brominated analogs of ilicicolins and azaphilones as well as iodinated analogs of azaphilones.

\section{Introduction}

Natural products have been sources of new active molecules for several decades, exploited in pharmacology, agrochemistry or cosmetology. One major challenge in natural product research is the ability to identify original compounds. For this purpose, it is possible to screen extract libraries to isolate new molecules [1], to diversify the chemical moiety from natural product skeleton by hemisynthesis [2], or to identify and use enzymes as biocatalysts [3]. An alternative method for discovering new biosynthesized molecular scaffolds is to explore unusual ecological niches and among the latter, insectassociated microorganisms are the target of a growing interest. Indeed, it is necessary to take into account that one million five thousand insect species (Arthropods) have been formally described to date [4]. Insects colonize almost all terrestrial habitats including forest, desert, coast... Moreover, these animals are known host numerous symbiotic microorganisms; these symbioses are found in different organs [5] such as cuticle, digestive system, glands... Until now, many insect-microorganisms interactions have been studied within eusocial insects named Apocrites (bees, wasps, ants) but few studies are still related to termite-microorganism association outside the trophobiosis $[6,7,8,9]$.

In the literature, the research group of V. Eparvier described examples of antimicrobial compounds produced by termite's symbiotic microorganisms $[6,10,11,12,13,14,15,16]$. Among the studied termiteassociated microorganisms, chlorinated metabolites of ilicicolin and azaphilone families were isolated from Neonectria discophora and Penicillium sclerotiorum fungal strains [14, 15, 16]. Halogenated natural products encompass many classes of compounds and have been mainly isolated from fungi from the marine environment. In the last decades, their pharmaceutical and medical applications have been explored and biological properties such as anticancer, antiviral, antibacterial, anti-inflammatory, antifungal, antifouling and insecticidal activities have been reported [17]. Furthermore, azaphilones are reported as antimicrobial compounds but also natural pigments [18, 19], and ilicicolins as antitrypanosomes or antimicrobials [20]. 
To highlight chlorinated compounds in our strain collection, we used dereplication strategy based on metabolomic approach [21]. In particular, molecular networks enable the clustering of tandem mass spectrometry (MS/MS) data according to their fragmentation profile similarity directly linked to the structural similarities of the related molecules [22]. Although these compounds can be annotated it is necessary to understand the biosynthetic pathways of these halogenated compounds to produce and generate molecular diversity in natural products $[23,24]$. To this end, recent advances in genomics can be used, such as next-generation sequencing methods, which allow routine sequencing and assembly of complete genomes of microorganisms [25]. The use of computational approaches such as antiSMASH [26] will allow the automatic detection of biosynthetic clusters of specialized metabolites in genomes. The goal being to be able to exploit enzymatic promiscuity to produce novel compounds from biosynthetic pathways $[27,28]$. Finally, in order to generate greater chemical diversity and produce cryptic specialized metabolites, the OSMAC (One Strain Many Compounds) method [29, 30, 31, 32] can be employed to increase the chemodiversity of halogenated compounds.

The objective of this study was to combine genomic and metabolomic approaches to study two families of halogenated polyketides produced by mutualistic fungal strains of termites from French Guiana, i.e. ilicicolines and azaphilones. This study allowed to annotate the chemodiversity of halogenated compounds, to propose biosynthetic pathways. This study also allowed to control the metabolism of the two model strains to produce original analogues of ilicicoline and azaphilone.

\section{Results And Discussion}

\section{Dereplication of Neonectria discophora SNB-CN63 metabolomes and Penicillium sclerotiorum SNB- CN111.}

The ICSN strain collection includes 130 strains of termite's mutualistic microorganisms from French Guiana. Each strain was cultivated on solid PDA medium and then extracted by ethyl acetate. The specialized metabolomes of each extract were explored by reverse-phase liquid chromatography hyphenated to positive electrospray ionization tandem mass spectrometry (RPLC-ESI(+)-MS/MS). The MS/MS data were organized and visualized as a molecular network, based on fragmentation spectra homology related to structural homology [22]. Using t-SNE visualization with MetGem software [33], the production of specialized metabolites with high structural specificity was analyzed. Indeed, ilicicolins produced by Neonectria discophora SNB-CN63 (blue cluster) and azaphilones produced by Penicillium sclerotiorum SNB-CN111 (red cluster) were highlighted (Figure 1).

In these two clusters we observed specific isotopic pattern of chlorinated metabolites via the natural abundance of ${ }^{37} \mathrm{Cl}$ isotope $(24.23 \%)$ versus ${ }^{35} \mathrm{Cl}(75.77 \%)$ were observed at the MS level [34]. Thereafter, in the blue colored cluster, 12 molecules have been annotated as ilicicolins by comparison with public or internal databases from previous studies (Table S1, Figure S1) $[14,15]$. Eight of these molecules are bearing a chlorine atom, such as LL-Z1272a or ilicicolinal (1), ilicicolinic acid A (2) and ilicicolinic acid C (3) (Figure 1). In the red colored cluster, twenty-three azaphilones were annotated using MS/MS spectral 
comparisons from public or in-house databases (Table S2, Figure S2) [16, 35, 36]. Among them, 14 are chlorinated, such as sclerotiorin (4), sclerotioramine (5) or 5-chloroisorotiorin (6) [37, 38, 39].

Ilicicolins are reported as intermediates of halogenated metabolites named ascofuranone and ascochlorin which are chlorinated by a FAD-dependent halogenase (AscD) [40]. In the literature, 28 ilicicolin or acid ilicicolinic scaffolds isolated from natural products are reported among which 22 are chlorinated [41].

In a review article published in 2021, Pavesi et al. reported 676 azaphilones among which 152 possess a chlorine atom [42]. These chlorinated metabolites are included in only four azaphilone subfamilies, i.e. chaetoviridins, falconensins, sclerotiorins and luteusins. Among these scaffolds, only the gene cluster involved in chaetoviridin biosynthesis has been elucidated. In that particular case, the enzyme involved in the chlorine addition is also a FAD-dependent halogenase (Cazl) [43].

Hence, we hypothesized is that FAD-dependent halogenases are catalyzing the halogenation of ilicicolins and azaphilones produced by $N$. discophora SNB-CN63 and P. sclerotiorum SNB-CN111, respectively [40, 43]. To look for these enzymes, we sequenced these two fungal genomes using a combined long and short-read sequencing approach followed by an hybrid assembly.

\section{N. discophora genome and ilicicolins biosynthetic pathway.}

The $N$. discophora genome (GCA_911649645) was obtained in 26 contigs covering $41.6 \mathrm{Mbp}$ and characterized by a GC content of $54.2 \%$. The completeness of the genome was established at $99.3 \%$ using the BUSCO score and 12,267 genes were predicted (Tables S3, S4) [44]. The contiguity of the genome assembly is characterized by an N50 length of $4.04 \mathrm{Mbp}$ and a L50 of 5 . We used the antiSMASH pipeline to predict the existence of a biosynthetic gene cluster, with $50 \%$ of its genes showing similarity to the ascofuranone biosynthesis gene cluster [26] was predicted by the antiSMASH pipeline [40]. This ilicicolins biosynthesis cluster is composed of 10 genes named Ndi_lli_A-J (Figure 2, Table S5).

The non-reducing polyketide synthase Ndi_lli_A predicted to catalyze orsellinic acid formation (7) shared $56 \%$ identity and $70 \%$ similarity with AscC, described in Acremonium egyptiacum [40]. The prenytransferase Ndis_lli_B produces grifolic acid (8) from orsellinic acid by the addition of a farnesyl group (observed at $[\mathrm{M}+\mathrm{H}]^{+}, \mathrm{m} / \mathrm{z} 373.2373$, err. $0.0 \mathrm{ppm}, \mathrm{C}_{23} \mathrm{H}_{32} \mathrm{O}_{4}$ ), and then a non-canonical nonribosomal peptide synthase Ndi_lli_C reduces the carboxylic acid function to form ilicicolin $\mathrm{B}$ also named LL-Z $1272 \beta$ (9) $\left([\mathrm{M}+\mathrm{H}]^{+}, \mathrm{m} / \mathrm{z} 357.2422\right.$, err. $\left.0.6 \mathrm{ppm}, \mathrm{C}_{23} \mathrm{H}_{32} \mathrm{O}_{3}\right)$. Finally, the FAD-dependent halogenase Ndis_lli_D, adds a chlorine atom on the orsellinic scaffold to form compounds 1 and/or $2\left([\mathrm{M}+\mathrm{H}]^{+}, \mathrm{m} / \mathrm{z}\right.$ 391.2028, err. 1.7 ppm, $\mathrm{C}_{23} \mathrm{H}_{31} \mathrm{ClO}_{3}$ and $[\mathrm{M}+\mathrm{H}]^{+}, \mathrm{m} / \mathrm{z}$ 407.1979, err. $1.1 \mathrm{ppm}, \mathrm{C}_{23} \mathrm{H}_{31} \mathrm{ClO}_{4}$, respectively) indicating also some flexibility of halogenase regarding its substrates (Table S6). It is likely that the formation of other compounds previously described in the literature from this strain [40], such as ilicicolinals and ilicolinic acids, involves the action of monooxygenase, epoxidase and terpene cyclase 
acting on the prenyl chain. These enzymes are probably located outside the Ndis_lli gene cluster, as determined by Araki et al. for ascochlorin and ascofuranone [40].

\section{P. sclerotiorum genome and azaphilone biosynthetic pathways.}

The genome of $P$. sclerotiorum SNB-CN111 (GCA_911649655) was obtained in 10 contigs covering a total size of $34.7 \mathrm{Mbp}$ and a GC content of $48.3 \%$. The completeness of the genome was established at $98.3 \%$ using BUSCO score and 12,582 genes were predicted (Tables S3, S4) [44]. The contiguity of the genome assembly is characterized by an N50 length of $4.34 \mathrm{Mbp}$ and a L50 of 4 . We used the antiSMASH pipeline to annotate a biosynthetic gene cluster including two polyketide synthases together with a halogenase was annotated in this genome using the antiSMASH pipeline [26]. This azaphilone biosynthesis gene cluster is composed of 13 genes named Psc_Aza_A-M (Figure 3, Tables S7, S8). The Psc_Aza_A protein was identified using a Pfam search as a highly reducing polyketide synthase composed of seven modules: ACP transacylase; $\beta$-ketoacyl synthase, acyltransferase, dehydratase, methyltransferase, dehydrogenase and keto-reductase. This sequence is typical of highly reducing polyketide synthases like ATEG_07659 (65\% identity, 77\% similarity) involved in the biosynthesis of azaphilones like asperfuranone [45]. The PSC_Aza_B gene is predicted to encode a non-reducing polyketide synthase composed of five modules: ACP transacylase, $\beta$-ketoacyl synthase, acyltransferase phosphopantetheine attachment site and methyltransferase. The enzyme CazM, a non-reducing polyketide synthase involved in chaetoviridin synthesis is the closest homolog (67\% identity, $78 \%$ similarity) to Psc_Aza_B [46]. Other azaphilone biosynthetic pathways involving a duo of highly reducing and non-reducing polyketide synthases are described in the literature [42]. These polyketide duos can operate sequentially [47], convergent [48] or hybrid [46]. Finally, Psc_Aza_C, a FAD dependent monooxygenase is found in the azaphilone biosynthetic gene cluster [42]. FAD-dependent monooxygenases play a key role in azaphilone synthesis, as they are required for the cyclization of the pyran ring. The high sequence similarity of the Psc_Aza_A/Psc_Aza_B polyketide synthases with the CasF/CazM and ATEG_07659/ATEG_07661 couples suggests that azaphilones biosynthetic pathway is similar to that of asperfuranone or chaetovirin.

Psc_Aza_A catalyzes the elongation of the 3,5-dimethyl-1,3-heptadienyl unit and then, the cyclization is performed by Psc_Aza_B. The monooxygenase Psc_Aza_C then catalyzes the cyclization of the pyran ring and the formation of the azaphilone scaffold (Figure 3 ). This hypothesis about the initiation of the azaphilones biosynthetic pathway is strengthened by the detection in the molecular network of an ion of $\mathrm{m} / \mathrm{z} 317.1747$ (err. $0.1 \mathrm{ppm}$ ) corresponding to the molecular formula $\mathrm{C}_{19} \mathrm{H}_{24} \mathrm{O}_{4}$ whose fragmentation spectrum agrees with the structure of metabolite 10 resulting from Psc_Aza_B catalysis (Figure S3). $[\mathrm{M}+\mathrm{H}]^{+}$ion of compound $\mathbf{1 1}$ is observed at $\mathrm{m} / z 333.1699$ (err. $0.8 \mathrm{ppm}$ ) and corresponding to the molecular formula $\mathrm{C}_{19} \mathrm{H}_{24} \mathrm{O}_{5}$ expected for the biosynthetic intermediate resulting from the biotransformation of metabolite 10 by Psc_Aza_C. The fragmentation spectrum of this ion at $m / z$ 333.1699 confirms the proposed structure of intermediate compound 11 (Figure S4). Metabolite 12, originating from the spontaneous conversion of metabolite 11 , was detected as a $[\mathrm{M}+\mathrm{H}]^{+}$ion at $\mathrm{m} / \mathrm{z}$ 
315.1594 (err. 1.0 ppm, $\mathrm{C}_{19} \mathrm{H}_{22} \mathrm{O}_{4}$ ) leading to a typical fragmentation spectrum from the sclerotiorin scaffold with a fragment at $m / z 147.0457$ (err. -7.9 ppm) and not observed up to now for compounds 10 and 11 (Figure S5) [16]. Molecule 12 is also described as an azaphilone intermediate involved in asperfuranone biosynthesis pathway [47].

Three biosynthetic pathways are possible from this azaphilone scaffold (12). The first pathway leads to the production of sclerotiorin (4). It is mediated by the action of an acyl transferase Psc_Aza_D to form compound $13\left([\mathrm{M}+\mathrm{H}]^{+}, m / z 357.1705\right.$, err. -2.4 ppm, $\left.\mathrm{C}_{21} \mathrm{H}_{24} \mathrm{O}_{5}\right)$. Then, the FAD-dependent halogenase Psc_Aza_H leads to the production of molecule $4\left([\mathrm{M}+\mathrm{H}]^{+}, \mathrm{m} / z 391.1309\right.$, err. $\left.-0.6 \mathrm{ppm}, \mathrm{C}_{21} \mathrm{H}_{23} \mathrm{ClO}_{5}\right)$. The second biosynthetic pathway leads to the formation of isochromophilone I (17) and is also initiated by the action of an acyltransferase, probably Psc_Aza_D which adds an acetoacetate to form compound $\mathbf{1 4}$ (not detected) that spontaneously converts by Knoevenagel condensation into the compound $\mathbf{1 5}\left([\mathrm{M}+\mathrm{H}]^{+}\right.$, $\mathrm{m} / \mathrm{z} 381.1691$, err. $1.5 \mathrm{ppm}, \mathrm{C}_{23} \mathrm{H}_{24} \mathrm{O}_{5}$ ) [42]. The angular lactone is then hydrogenated by the action of Psc_Aza_F or $\mathrm{G}$ to form compound $16\left([\mathrm{M}+\mathrm{H}]^{+}, \mathrm{m} / z 383.1859\right.$, err. $\left.-1.6 \mathrm{ppm}, \mathrm{C}_{23} \mathrm{H}_{26} \mathrm{O}_{5}\right)$ which is then chlorinated by the action of Psc_Aza_H. The third biosynthetic pathway leads to the formation of compound $\mathbf{2 0}$. The formation of molecule $\mathbf{2 0}$ requires the action of an oxidoreductase to reduce C- 6 ketone and form a hydroxyl, a dehydrogenase to hydrogenate the $\mathrm{C}-1 / \mathrm{C}-8 \mathrm{a}$ bond as well as an acyltransferase and a halogenase. However, without the detection of intermediates between compounds 12 and 19, it is not possible to define which enzymes are involved and in which order. The enzymes Psc_Aza_D, E, F/G could be involved in the biosynthesis of metabolites 12 to 19 because of their Pfam domains and their inclusion in the azaphilones biosynthetic gene cluster. Finally, Psc_Aza_H catalyzes the chlorination of molecule $19\left([\mathrm{M}+\mathrm{H}]^{+}, \mathrm{m} / \mathrm{z} 361.2021\right.$, err. $\left.-3.2 \mathrm{ppm}, \mathrm{C}_{21} \mathrm{H}_{28} \mathrm{O}_{5}\right)$ to form compound 20 $\left([\mathrm{M}+\mathrm{H}]^{+}, m / z\right.$ 395.1626, err. $\left.-1.6 \mathrm{ppm}, \mathrm{C}_{21} \mathrm{H}_{27} \mathrm{ClO}_{5}\right)$. Finally, compound 21, the chlorinated analog of intermediate $12\left(\mathrm{~m} / z\right.$ 349.1205, err. $\left.-1.1 \mathrm{ppm}, \mathrm{C}_{19} \mathrm{H}_{21} \mathrm{ClO}_{4}\right)$ is also detected (Figure S6), suggesting that the FAD-dependent halogenase Psc_Aza_H may be involved as the formation of azaphilone scaffold.

Therefore, we completed the annotation of the biosynthetic gene cluster of sclerotiorin (4) and isochromophilone I (17) was completed. Both compounds originating from an intermediate with a minimal azaphilone scaffold with a 3,5-dimethyl-1,3-heptadienyl chain (molecule 12) that is typical of sclerotiorin and its analogs (Figure 3). The gene coding for a halogenase, Psc_Aza_H was identified, as well as numerous chlorinated azaphilone intermediates or analogs (Tables S2, S7). The FAD-dependent halogenase may be involved as early as the formation of azaphilone scaffold since the intermediate $\mathbf{2 1}$ is the chlorinated analog of compound 12.

To sum up, we identified two clusters of biosynthetic genes responsible for the production of two chlorinated polyketide families: ilicicolins and azaphilones. For each cluster, we annotated a FADdependent halogenase. We then set up an OSMAC method to generate structural diversity and to confirm the ability of halogenases in the biosynthetic pathways to introduce various halogens $(\mathrm{Cl}, \mathrm{Br}$ and I), an OSMAC method was set up. 


\section{Generation of undescribed halogenated compounds using OSMAC method.}

Several studies have highlighted the ability of FAD-dependent halogenases to introduce different halogens such as $\mathrm{Cl}, \mathrm{Br}$ and I into various chemical scaffolds $[49,50]$. Therefore, we sought to generate new compounds taking into account this biosynthetic possibility from our two sequenced strains: $N$. discophora SNB-CN63 and P. sclerotiorum SNB-CN111. For this purpose, we cultivated strains on PDA media supplemented with $10 \mathrm{~g} . \mathrm{L}^{-1} \mathrm{NaCl}, \mathrm{KBr}$ or KI. We further analyzed crude extracts were further analyzed by RPLC-ESI(+)-MS/MS to highlight and annotated the major halogenated biosynthesized analogs (Figure 4a).

We searched the $m / z$ values of the protonated species corresponding to the halogenated $(\mathrm{Cl}, \mathrm{Br}$ and $\mathrm{I})$ metabolites were searched in the MS data. We also examined the isotopic profiles and the retention time (RT) which evolves with sizes of the halogen substituting $\mathrm{H}$, i.e. $\mathrm{H}<\mathrm{Cl}<\mathrm{Br}<1$. For example; all azaphilone analogs with $\mathrm{H}, \mathrm{Cl}, \mathrm{Br}$, and I at $\mathrm{C}-5$ position for scaffold $\mathrm{A}^{\prime}$ (Figure $4 \mathrm{a}$ ) were detected from $P$. sclerotiorum crude extracts when the corresponding halogen was added to the culture medium. The same approach was applied to $N$. discophora crude extract and demonstrated that the Ndis_lli_D halogenase is also able to catalyze the addition of $\mathrm{Cl}$ and $\mathrm{Br}$ to ilicicolins. However, we did not detect any no signals related to iodinated species were detected for scaffolds A and B (Figures $4 b, S 7, S 8$ ). Similar results to scaffold A' were obtained for azaphilone scaffolds B', C', D', and E' (Figures 4c, S9-S11) confirming that Psc_Aza_H can efficiently halogenate azaphilone sub-families with $\mathrm{Cl}, \mathrm{Br}$ and $\mathrm{I}$.

We performed a scale up culture to confirm our structural annotations and to demonstrate that halogenase promiscuity can be exploited to produce sufficient quantities of isolable compounds. We used Czapek medium (Czk) to scale-up culture of $P$. sclerotiorum because no organic nitrogen is provided in this medium thereby leading to a reduced number of produced metabolites. As brominated molecules from scaffold $B^{\prime}$ and $E^{\prime}$ have already been described, we focused on scaffold $A^{\prime}[51,52,53]$. Furthermore, nitrogenated azaphilones like molecules bearing the scaffold $\mathrm{D}^{\prime}$ are not produced in Czk medium and bromine molecules related to scaffold $C^{\prime}$ were not abundant enough. Therefore compound $\mathbf{2 2}$ related to scaffold $A^{\prime}$ and having incorporated bromine was produced and isolated. Compound $\mathbf{2 2}$ was obtained as an orange oil; its molecular formula was determined as $\mathrm{C}_{23} \mathrm{H}_{23} \mathrm{BrO}_{5}$ based on the ESI-HRMS experiment $\left([\mathrm{M}+\mathrm{H}]^{+}\right.$peak at $\mathrm{m} / \mathrm{z} 459.0798$ calcd for $\mathrm{C}_{23} \mathrm{H}_{23} \mathrm{BrO}_{5} \mathrm{H}^{+}$, err. $0.7 \mathrm{ppm}$ ) (Figure 5). Azaphilones scaffold was identified by observation in ${ }^{13} \mathrm{C}$ NMR of carbon with chemical shifts at $\delta_{\mathrm{C}} 153.2,159.7$ and 184.5 (C1, C-3 and C-6 respectively) and validated by HMBC correlations of $\mathrm{H} 1 / \mathrm{C}-3, \mathrm{C}-4 \mathrm{a}$, and C-8a, H4/C-3, C-5, C8, C-8a and finally H18/C-6, C-7 and C-8. In addition, the HMBC correlations of $\mathrm{H}-9, \mathrm{H}-10$ with $\mathrm{C}-3$ and $\mathrm{H}-4$ with $\mathrm{C}-3$ allowed to connect the side chain. The lactone moiety was confirmed by the presence of 4 carbons including 2 carbonyls observed at $\delta_{C} 195.1$ and 169.4, one methene (at $\delta_{C} 124.8$ ), one methyl group $\left(\delta_{C} 30.9\right)$ and by HMBC correlations between $\mathrm{H}-5^{\prime}$ and $\mathrm{C}-\mathrm{3}^{\prime}$ and $\mathrm{C}-\mathrm{C}^{\prime}$. The 3,5-dimethyl-1,3heptadienyl unit was established by typical correlations of trans-coupled olefinic protons observed in COSY with correlations between $\mathrm{H}-9 / \mathrm{H}-10 ; \mathrm{H}-12 / \mathrm{H}-13 / \mathrm{H}-16$ and $\mathrm{H}-13 / \mathrm{H}-14 / \mathrm{H}-15$. As no proton is observed at the $\mathrm{C}-5$ position on the HSQC spectrum, the bromine atom has been positioned there (Figures 
S13-18). This attribution is in accordance with the reported NMR characterization of compounds with the same scaffolds like 15 and $6[39,51]$. Compound 22 was named 5-bromoisorotiorin.

So far, the isolation and identification of brominated azaphilones was described in only three publications, and all of them reported the isolation from marine sponge-derived fungus of Penicillium genus ( $P$. janthinellum and $P$. canescens) $[54,55]$. The authors cultivated these strains with $\mathrm{NaBr}$ to obtain these five brominated azaphilones. The brominated metabolite $\mathbf{2 2}$ was also obtained by an OSMAC method using halogenase promiscuity but for the first time from a terrestrial fungus.

In a previous study concerning mutualistic strains isolated from termites, we had shown that the PDA extract of SNB-CN111 had antifungal activity on Trychophyton rubrum [16]. Therefore, we test the antimicrobial activitiy of isolated compounds : 5-chloroisorotiorin, 5-bromoisorotiorin and sclerotiorin on the same human pathogen. We evidenced a potent antimicrobial activities with MIC values of $32 \mu \mathrm{g} / \mathrm{mL}$ for extract and individual compounds. Therefore, the presence (or not) of halogens on azaphilone scaffolds does not seem modulating the antimicrobial activity but offers the opportunity to diversify the accessible bioactive compounds from this particular molecular family.

\section{Conclusion}

We uncovered two families of halogenated polyketides: azaphilone and ilicicolin derivatives by the metabolomic analysis of a collection of 130 extracts strain from microorganisms associated with French Guiana termites and the reconstruction of molecular network using t-SNE.

We sequenced and assembled the whole genomes of the two fungal strains producing such halogenated metabolites, $P$. sclerotiorum SNB-CN111 and N. discophora SNB-CN63. We annotated two biosynthetic gene clusters related to azaphilones and ilicicolins, and we showed that chlorine addition in both biosynthetic pathways was catalyzed by an halogenase, as described for molecules belonging to the same families [40, 42]. Then, we used of RPLC-ESI(+)-MS/MS data to annotate biosynthetic intermediates not isolable in the crude extracts or fractions due to low concentrations, reinforcing the biosynthetic pathway hypotheses. These data allowed the identification of a high molecular diversity of halogenated polyketides.

FAD-dependent halogenases promiscuity was exploited in our study to generate original chlorinated, brominated or iodinated analogs. One of the brominated compound was isolated and characterized and permitted to confirm our annotations of halogenated compounds in the molecular networks generated.

Thus, the possibility of using halogenases to catalyze environmentally friendly and regio-selective halogenations is an attractive alternative to classical halogenation processes $[50,56]$. It will thus be relevant to test the ability of the halogenases Psc_Aza_H and Ndi_lli_D to introduce halogens to chemical backbones different from azaphilone or iliciolin ones, as well as to organic synthesis intermediates like substituted benzenes. As it seems that halogenase Psc_Aza_H is able to catalyze the halogen addition as 
soon as the formation of the azaphilone scaffold, this enzyme could be integrated in other azaphilone biosynthetic gene cluster to generate more molecular diversity using metabolic engineering.

\section{Methods}

General Experimental Procedures. Optical rotations were measured at $20^{\circ} \mathrm{C}$ in methanol using an Anton Paar MCP 300 polarimeter in a $100 \mathrm{~mm}$ long $350 \mu \mathrm{L}$ cell. UV spectra were recorded at $20^{\circ} \mathrm{C}$ in $\mathrm{MeOH}$ using a PerkinElmer Lambda 5 spectrophotometer. NMR spectra were recorded on Bruker $700 \mathrm{MHz}$ spectrometers (Bruker, Rheinstetten, Germany). The chemical shifts $(\delta)$ are reported as ppm based on the solvent signal, and coupling constants $(\mathrm{J})$ are in hertz. Preparative HPLCs was conducted with a Gilson system equipped with a 322 pumping device, a GX-271 fraction collector, a 171 diode array detector, and a prep ELSII. All solvents were HPLC grades, purchased from Sigma-Aldrich (Saint-Quentin-Fallavier, France).

Isolation and identification of termite mutualistic microorganisms. The taxonomic marker analyses were performed by BACTUP, France. The identification of the fungi was conducted by amplification of the ITS4 or ITS1 region of ribosomal DNA and the bacterial isolates were identified on the basis of 16S rDNA sequence analysis. These sequences were compared to the non-redundant nucleotide collection using BLASTN 2.12 (http://www.ncbi.nlm.nih.gov, accessed on August 17, 2021).

The SNB-CN63 strain was isolated from Nasutitermes corniger termite aerial nest sampled in Sentier des Salines in French Guiana. A DNA sample from SNB-CN63 was used for strain identification following nuclear ribosomal internal transcribed spacer region ITS4 sequencing and sequence comparison. The obtained sequence (accession number KJ023733) was $96 \%$ identical over 558 bp to FJ560438.1 from Neonectria discophora and therefore this strain SNB-CN63 from the strain library collection at ICSN was identified as Neonectria discophora.

The SNB-CN111 strain was isolated from Nasutitermes similis termite aerial nest sampled in Piste de Saint-Elie in French Guiana. We used the same approach described for SNB-63 to obtain the taxonomic identity of SNB-C111. The obtained ITS sequence (acc. number KJ023726) was $97 \%$ identical to KX365203.1 from Penicillum sclerotium and therefore this strain SNB-CN63 from the strain library collection at ICSN was identified as Penicillium sclerotiorum.

Genomic DNA extraction of Penicillium sclerotiorum SNB-CN111 and Neonectria discophora SNB-CN63. For high molecular weight gDNA extraction, we cultivated the strains Penicillium sclerotiorum SNB-CN111 and Neonectria discophora SNB-CN63 on PDA medium on permeable cellophane membrane prepared as described by Fauchery et al.[57]. The cellophane membranes were trimmed to the size of the petri dish, put into boiling distilled water containing EDTA $\left(1{\mathrm{~g} . \mathrm{L}^{-1}}^{-1} 20 \mathrm{~min}\right.$ in order to permeabilize the membrane, rinsed four times in a big container with distilled water and autoclaved. After 7 days at $26^{\circ} \mathrm{C}$ microorganisms were removed from cellophane membrane, snap freezed in liquid nitrogen and milled using mortar and pestle. 
gDNA was extracted from microorganisms using NucleoBond Buffer Set III and AXG 100 (MachereyNagel, Hoerdt, France) with slight modifications: $250 \mathrm{mg}$ of milled mycelium were resuspended in $5 \mathrm{~mL}$ of buffer $\mathrm{G} 3,37^{\circ} \mathrm{C}$ for $14 \mathrm{~h}, 1.2 \mathrm{~mL}$ of buffer $\mathrm{G} 4$ was added and the solution was gently mixed then incubated at $50^{\circ} \mathrm{C}$ for 4 hours. Sample was clarified through centrifugation $5000 \mathrm{~g}, 5 \mathrm{~min}$. After ethanol precipitation, samples were re-dissolved in $100 \mu \mathrm{L}$ of nuclease free water. Purity was measured using a Nanodrop 2000 spectrophotometer, and DNA quantity was measured using a Qubit dsDNA BR assay kit according to the manufacture's recommendation and a Qubit fluorometer. The integrity of DNA was assessed by electrophoresis on a on $0.7 \%$ agarose gel in TBE $0.5 \mathrm{X}$. We performed an additional size selection and cleanup for $N$. discophora SNB-CN63 DNA using the Circulomics Short Read Eliminator kit (www.circulomics.com).

Whole genome sequencing and hybrid assembly. P. sclerotiorum SNB-CN111 and $N$. discophora SNBCN63 DNA samples were prepared for shotgun sequencing according to native barcoding expansion (EXP-NBD-103) and the 1D Native barcoding genomic DNA protocol (SQK-LSK109). We loaded 50 femtomoles of purified pooled library on a FLO-MIN111 flowcell (R10.3, Oxford Nanopore Technologies) and ran the sequencing for 72 hours.

Short read DNA sequencing was outsourced to Novogene (https://en.novogene.com/). The same DNA used for long-read sequencing was fragmented (mean size of $350 \mathrm{bp}$ ) and sequenced using a paired-end strategy on an Illumina NovaSeq 6000 to obtain two 150 nt reads per DNA fragment. Overall, we obtained an estimated coverage of $304 \mathrm{X}$ for CN63 (143X and 161X for short and long reads, respectively) and 191X for CN111 (38X and 153X for short and long reads sequencing, respectively).

We performed basecalling and adapter trimming using Guppy 3.2.10 for long reads, and checked raw reads quality using NanoPlot [58]. Finally, we used WenganM for genome assembly [59]. By this analysis SNB-CN63 was identified as Thelonectria discophora." Neonectria"discophora var. rubi belongs to Thelonectria; however, it has not been formally transferred to this genus [60].

Culture and extraction of microorganisms. All strains were cultivated on solid PDA medium at $26^{\circ} \mathrm{C}$ for 15 days, on four Petri dishes of $10 \mathrm{~cm}$ diameter $\left(85 \mathrm{~cm}^{2}\right)$. For the OSMAC experiments, the microorganisms were cultivated under the identical conditions on four Petri dishes of $10 \mathrm{~cm}$ diameter $\left(85 \mathrm{~m}^{2}\right)$ with PDA medium supplemented of $10 \mathrm{~g} . \mathrm{L}^{-1}$ of $\mathrm{NaCl}, \mathrm{KBr}$ and $\mathrm{KI}$. For the large-scale culture of $P$. sclerotiorum the microorganism was cultivated under identical conditions on 60 Petri dishes of $10 \mathrm{~cm}$ diameter $\left(85 \mathrm{~m}^{2}\right)$ with Czapek medium supplemented of $10{\mathrm{~g} . \mathrm{L}^{-1}}^{-1}$ of $\mathrm{KBr}$. The contents of the Petri dishes were transferred into a large container and macerated with EtOAc for $24 \mathrm{~h}$. Insoluble residues were removed via filtration and the organic phase was washed three times with an equivalent volume of water $\left(\mathrm{H}_{2} \mathrm{O}\right)$, dried with anhydrous solid $\mathrm{Na}_{2} \mathrm{SO}_{4}$ then evaporated using a rotary evaporator under reduced pressure and temperature of $30^{\circ} \mathrm{C}$.

Halogenated compound isolation and characterization. The whole crude extract of $P$. sclerotiorum cultivated on Czapek supplemented by $\mathrm{KBr} 10 \mathrm{~g} \cdot \mathrm{L}^{-1}(1.2 \mathrm{~g})$ was fractionated by reversed-phase flash 
chromatography (Grace Reveleris, Grace, Maryland, USA) using a 120 grams C18 column and ultraviolet (UV) and evaporative light scattering detector (ELSD) detectors. A linear gradient of a mixture of solvent $A$ $\left(\mathrm{H}_{2} \mathrm{O} /\right.$ formic acid $\left.99.9 / 0.1\right)$ and solvent $B$ (acetonitrile/formic acid $(99.9 / 0.1)$ ), from $5 \%$ of solvent $B$ to $100 \%$ in $40 \mathrm{~min}$, flow rate at $80 \mathrm{~mL} \cdot \mathrm{min}^{-1}$ ); followed by a second gradient of solvent $B$ and solvent $C$ (methylene chloride), from $50 \%$ of $C$ to $100 \%$ in $15 \mathrm{~min}$, flow rate at $80 \mathrm{~mL} \cdot \mathrm{min}^{-1}$, were performed to generate eight fractions labeled F1 to F8. Fraction of interest F6 (60 mg) was submitted to preparative HPLC. Fraction F6 was purified using an isocratic condition of solvent B $80 \%$ for 40 min and led to the isolation of the new compound $22\left(2.5 \mathrm{mg}, t_{R}=28.6 \mathrm{~min}\right)$.

5-Bromoisorotiorin (22): orange amorphous oil; $[\mathrm{a}]^{20}{ }_{\mathrm{D}} 330\left(\mathrm{c} 0.1 \mathrm{~g} . \mathrm{L}^{-1}, \mathrm{MeOH}\right), \mathrm{UV}(\mathrm{MeOH}) \lambda \max (\varepsilon), 380$ (5 800 L.mol $\left.{ }^{-1} \cdot \mathrm{cm}^{-1}\right), 422\left(6000\right.$ L.mol$\left.{ }^{-1} \cdot \mathrm{cm}^{-1}\right),{ }^{1} \mathrm{H}$ NMR $(700 \mathrm{MHz}, \mathrm{DMF}) \delta \mathrm{H} 8.82(1 \mathrm{H}, \mathrm{s}, \mathrm{H}-1), 6.98(1 \mathrm{H}, \mathrm{s}$, $\mathrm{H}-4), 6.78(1 \mathrm{H}, \mathrm{d}, \mathrm{J}=16.1 \mathrm{~Hz}, \mathrm{H}-9), 7.26(1 \mathrm{H}, \mathrm{d}, \mathrm{J}=16.2 \mathrm{~Hz}, \mathrm{H}-10), 5.87(1 \mathrm{H}, \mathrm{d}, \mathrm{J}=10.2 \mathrm{~Hz}, \mathrm{H}-12), 2.55(1 \mathrm{H}$, m, H-13), 1.45 (1H, m, H-14a), $1.34(1 \mathrm{H}, \mathrm{m}, \mathrm{H}-14 \mathrm{~b}), 0.87(3 \mathrm{H}, \mathrm{t}, \mathrm{J}=7.4 \mathrm{~Hz}, \mathrm{H}-15), 1.02(3 \mathrm{H}, \mathrm{d}, \mathrm{J}=6.7 \mathrm{~Hz}, \mathrm{H}-$ 16), 1.92 (3H, s, H-17), 1.72 (3H, s, H-18), 2.57 (3H, s, H-5),${ }^{13} \mathrm{C}$ NMR (700 MHz, DMF) $\delta_{\mathrm{C}} 153.2$ (CH, C-1), 159.7 (C, C-3), 109.5 (CH, C-4), 143.4 (C, C-4a), 100.8 (C, C-5), 184.5 (C, C-6), 88.4 (C, C-7), 164.2 (C, C-8), 112.1 (C, C-8a), 118.1 (CH, C-9), 143.6 (CH, C-10), 133.9 (C, C-11), 149.1 (CH, C-12), 35.9 (CH, C-13), 30.3 $\left(\mathrm{CH}_{2}, \mathrm{C}-14\right), 12.5\left(\mathrm{CH}_{3}, \mathrm{C}-15\right), 20.8\left(\mathrm{CH}_{3}, \mathrm{C}-16\right), 12.9\left(\mathrm{CH}_{3}, \mathrm{C}-17\right), 26.4\left(\mathrm{CH}_{3}, \mathrm{C}-18\right), 169.4\left(\mathrm{CH}_{2}, \mathrm{C}-2^{\prime}\right), 124.8$ (C, C-3'), $195.2\left(\mathrm{C}, \mathrm{C}-4^{\prime}\right), 30.5\left(\mathrm{CH}_{3}, \mathrm{C}-5^{\prime}\right)$, ESI-HRMS $\mathrm{m} / \mathrm{z}[\mathrm{M}+\mathrm{H}]^{+} 459.0798$ (calcd for $\mathrm{C}_{23} \mathrm{H}_{22} \mathrm{BrO}_{5} \mathrm{H}^{+}$, 459.0802, err. -0.7 ppm).

RPLC-ESI(+)-MS/MS analysis. Crude extracts of all SNB-CN strains cultivated and extracted as previously described together with fractions from Penicillium sclerotiorum SNB-CN111 were prepared at $1 \mathrm{mg}^{\mathrm{mL}} \mathrm{mL}^{-1}$ in methanol and filtered on $0.45 \mu \mathrm{m}$ PTFE membrane. RPLC-ESI(+)-MS/MS experiments were performed with a 1260 Prime HPLC (Agilent Technologies, Waldbronn, Germany) coupled with an Agilent 6540 QToF (Agilent Technologies, Waldbronn, Germany) tandem mass spectrometer. RPLC separation was achieved with an Accucore RP-MS column $(100 \times 2.1 \mathrm{~mm}, 2.6 \mu \mathrm{m}$, Thermo Scientific, Les Ulis, France) with a mobile phase consisting of $\mathrm{H}_{2} \mathrm{O} /$ formic acid (99.9/0.1) (A)-acetonitrile/formic acid (99.9/0.1) (B). The column oven was set at $45^{\circ} \mathrm{C}$. Compounds were eluted at a flow rate of $0.4 \mathrm{~mL}$. $\mathrm{min}^{-1}$ with a gradient from $5 \%$ B to $100 \%$ B in $20 \mathrm{~min}$ and then $100 \%$ B for $3 \mathrm{~min}$. Injection volume was fixed at $5 \mu \mathrm{L}$ for all analyses. For electrospray ionization source, mass spectra were recorded in positive ion mode with the following parameters: gas temperature $325^{\circ} \mathrm{C}$, drying gas flow rate $10 \mathrm{~L} \cdot \mathrm{min}^{-1}$, nebulizer pressure $30 \mathrm{psi}$, sheath gas temperature $350^{\circ} \mathrm{C}$, sheath gas flow rate $10 \mathrm{~L}$. $\mathrm{min}^{-1}$, capillary voltage $3500 \mathrm{~V}$, nozzle voltage $500 \mathrm{~V}$, fragmentor voltage $130 \mathrm{~V}$, skimmer voltage $45 \mathrm{~V}$, Octopole $1 \mathrm{RF}$ Voltage $750 \mathrm{~V}$. Internal calibration was achieved with two calibrants purine and hexakis (1h,1h,3h-tetrafluoropropoxy)phosphazene $(\mathrm{m} / \mathrm{z}$ 121.0509 and $m / z$ 922.0098) providing a high mass accuracy better than $10 \mathrm{ppm}$. The data-dependent MS/MS events were acquired for the five most intense ions detected by full-scan MS, from 200-1000 m/ $z$ range, above an absolute threshold of 1000 counts. Selected precursor ions were fragmented at a fixed collision energy of $30 \mathrm{eV}$ and with an isolation window of $1.3 \mathrm{amu}$. The mass range of the precursor and fragment ions was set as $m / z 200-1000$. 
Isolated compounds from Penicillium sclerotiorum SNB-CN111 fractions were prepared at $0.05 \mathrm{mg} \cdot \mathrm{mL}^{-1}$ in methanol and filtered on $0.45 \mu \mathrm{m}$ PTFE membrane. The isolated compounds were analyzed according to the same procedure.

Data processing and analysis. The data files were converted from the.$d$ standard data format (Agilent Technologies) to .mzXML format using the MSConvert software, part of the ProteoWizard package 3.0 [61]. All .mzxml were processed using MZmine2v53 as previously described [62, 63]. The mass detection was realized with MS1 noise level at 1000 and MS/MS noise level at 0 . The ADAP chromatogram builder was employed with a minimum group size of scans of 3, a group intensity threshold of 1000, a minimum highest intensity of 1000 , and $\mathrm{m} / \mathrm{z}$ tolerance of 0.008 (or $20 \mathrm{ppm}$ ). Deconvolution was performed with the ADAP wavelets algorithm according to the following settings: $S / N$ threshold $=10$, minimum features height=1000, coefficient/area threshold=10, peak duration range $0.01-1.5 \mathrm{~min}, t_{R}$ wavelet range 0.00-0.04 min. MS/MS scans were paired using an $\mathrm{m} / z$ tolerance range of $0.05 \mathrm{Da}$ and $t_{R}$ tolerance range of 0.5 $\mathrm{min}$. Isotopologues were grouped using the isotopic peak grouper algorithm with an $\mathrm{m} / \mathrm{z}$ tolerance of 0.008 (or $20 \mathrm{ppm}$ ) and a $t_{R}$ tolerance of $0.2 \mathrm{~min}$. Peaks were filtered using Feature list row filter, keeping only peaks with MS/MS scans (GNPS). Peak alignment was performed using the join aligner with an $\mathrm{m} / \mathrm{z}$ tolerance of 0.008 (or $20 \mathrm{ppm}$ ), a weight for $\mathrm{m} / \mathrm{z}$ at 20, a retention time tolerance of $0.2 \mathrm{~min}$, and weight for $t_{R}$ at 50. The MGF file and the metadata were generated using the export/submit to GNPS option.

Molecular networks were calculated and visualized using MetGem 1.34 software [33], MS/MS spectra were window-filtered by choosing only the top 6 peaks in the $\pm 50 \mathrm{Da}$ window throughout the spectrum. The data were filtered by removing all peaks in the $\pm 17 \mathrm{Da}$ range around the precursor $\mathrm{m} / \mathrm{z}$. The $\mathrm{m} / \mathrm{z}$ tolerance windows used to find the matching peaks was set to $0.02 \mathrm{Da}$, and cosine scores were kept in consideration for spectra sharing 2 matching peaks at least. The number of iterations, perplexity, learning-rate, and early exaggeration parameters were set to $5000,25,200$, and 12 for t-SNE view.

Figures were generated using $\mathrm{R}$ and related packages (ggplot2, Rcolorbrewer, and gridextra), MetGem export function, and ChemDraw Professional 16.0 (PerkinElmer). NMR spectra were processed and analyzed using TopSpin 3.6.2 (Bruker, Rheinstetten, Germany).

Biological Assays. Pure isolated compounds were tested on the human pathogenic microorganism Trichophyton rubrum (SNB-TR1) this clinical isolate was provided by Phillipe Loiseau (University ParisSaclay, Châtenay-Malabry, France). Extracts, fractions, and pure compounds were tested according to the reference protocol of the European Committee on Antimicrobial Susceptibility Testing [64]. The minimal inhibitory concentration value was obtained after $72 \mathrm{~h}$. The MIC values reported refer to the lowest concentration preventing visible growth in the wells. Pure compounds were tested at concentrations ranging from 256 to $0.5 \mu \mathrm{g} \cdot \mathrm{mL}^{-1}$. All assays were conducted in duplicate. Itraconazole $\left(\mathrm{MIC}=4 \mu \mathrm{g} \cdot \mathrm{mL}^{-1}\right)$ was used as positive controls.

\section{Declarations}




\section{Author contributions statement}

Conceptualization, T.H., D.T., V.E.; methodology, T.H., N.P., D.T., V.E, validation, T.H., N.P., D.T., V.E.; formal analysis, T.H.; investigation, T.H., N.P., D.T., V.E.; resources, D.T., V.E.; data curation, T.H., N.P., D.T., V.E.; writing-original draft preparation, T.H., V.E.; writing-review and editing, D.T., V.E.; visualization, T.H., V.E.; supervision, D.T., V.E.; project administration, D.T., V.E.; funding acquisition, D.T., V.E. All authors have read and agreed to the published version of the manuscript.

\section{Acknowledgements}

Téo Hebra thanks the ministère de l'Enseignement supérieur, de la Recherche et de l'Innovation (MESRI) for his PhD fellowship. This work was supported by an "Investissement d'Avenir" grant (CEBA, ref ANR-10LABX-0025) managed by the French National Research Agency (ANR).

\section{Competing interests}

The authors declare no competing interests.

\section{Data Availability}

The datasets generated during the current study are available in the 'European Nucleotide Archive' [ENA] repository at http://www.ebi.ac.uk/ena/browser/view/<PRJEB46500>

ASSEMBLY_NAME | ASSEMBLY_ACC | STUDY_ID | SAMPLE_ID | CONTIG_ACC | SCAFFOLD_ACC | CHROMOSOME_ACC wengan_M_CN63 | GCA_911649645 | PRJEB46500 | ERS6673250 | CAJVRK010000001CAJVRK010000026 | repository at

https://www.ebi.ac.uk/ena/browser/view/GCA_911649645.1

wengan_M_CN111 | GCA_911649655 | PRJEB46500 | ERS6673251 | CAJVRJ010000001CAJVRJ010000010 | repository at https://www.ebi.ac.uk/ena/browser/view/GCA_911649655.1

Correspondence and requests for materials should be addressed to V.E. or D.T.

\section{References}

1. Chiocchio, I. et al. Screening of a hundred plant extracts as tyrosinase and elastase inhibitors, two enzymatic targets of cosmetic interest. Ind. Crops Prod., 122, 498-505 (2018).

2. Davison, E. K. \& Brimble, M. A. Natural product derived privileged scaffolds in drug discovery. Curr. Opin. Chem. Biol., 52, 1-8 (2019).

3. Aleku, G. A. et al. A reductive aminase from Aspergillus oryzae. Nat. Chem. 9, 961-969 (2017). 
4. Stork, N. E., McBroom, J., Gely, C. \& Hamilton, A. J. New approaches narrow global species estimates for beetles, insects, and terrestrial arthropods. Proc. Natl. Acad. Sci. U.S.A., 112, 7519-7523 (2015).

5. Brune, A. Symbiotic digestion of lignocellulose in termite guts. Nat. Rev. Microbiol., 12, 168-180 (2014).

6. Beemelmanns, C., Guo, H., Rischer, M. \& Poulsen, M. Natural products from microbes associated with insects. J. Org. Chem., 12, 314-327 (2016).

7. Dillon, R. J. \& Dillon, V. M. The gut bacteria of insects: nonpathogenic interactions. Annu. Rev. Entomol., 49, 71-92 (2004).

8. Matsui, T., Tanaka, J., Namihira, T. \& Shinzato, N. Antibiotics production by an actinomycete isolated from the termite gut. J. Basic Microbiol., 52, 731-735 (2012).

9. Zhang, Y. et al. Antifungal activities of metabolites produced by a termite-associated Streptomyces canus BYB02. J. Agric. Food Chem., 61, 1521-1524 (2013).

10. Nirma, C., Eparvier, V., Stien, D. Antifungal agents from Pseudallescheria boydii SNB-CN73 isolated from a Nasutitermes sp. termite J. Nat. Prod. 76, 988-991 (2013).

11. Nirma, C., Eparvier, V. \& Stien, D. Reactivation of antibiosis in the entomogenous fungus Chrysoporthe sp. SNB-CN74. J. Antibiot. 68, 586-590 (2015).

12. Sorres, J., Nirma, C., Eparvier, V. \& Stien, D. Pseudallicins A-D, four complex ovalicin derivatives from Pseudallescheria boydii SNB-CN85. Org. Lett. 9, 3978-3981. (2017).

13. - Sorres, J., Nirma, C., Eparvier, V. \& Stien, D. Tyroscherin and tyroscherin analogs from Pseudallescheria boydii SNB-CN85 isolated from termite Termes cf. hispaniolae. Phytochem. Lett. 22, 142-144 (2017).

14. Nirma, C., Eparvier, V. \& Stien, D. Antibacterial ilicicolinic acids C and D and ilicicolinal from Neonectria discophora SNB-CN63 isolated from a termite nest. J. Nat. Prod., 78, 159-162 (2015).

15. Sorres, J., Sabri, A., Brel, O., Stien, D. \& Eparvier, V. Ilicicolinic acids and ilicicolinal derivatives from the fungus Neonectria discophora SNB-CN63 isolated from the nest of the termite Nasutitermes corniger found in French Guiana show antimicrobial activity. Phytochemistry, 151, 69-77 (2018).

16. Hebra, T. et al. Dereplication, Annotation, and characterization of 74 potential antimicrobial metabolites from Penicillium Sclerotiorum using t-SNE Molecular Networks. Metabolites, 11, 444 (2021).

17. Wang, C., Lu, H., Lan, J., Zaman, KH. A. \& Coa, S. A review: halogenated compounds from marine fungi. Molecules 26, 458 (2021).

18. Mapari, S. A. S., Thrane, U. \& Meyer, A. S. Fungal polyketide azaphilone pigments as future natural food colorants? Trends Biotechnol., 28, 300-307 (2010).

19. Chen, C., et al. Recent advances in chemistry and biology of azaphilones. RSC Adv. 10, 10197-10220 (2020).

20. Nihei, C., Fukai, Y. \& Kita, K. Trypanosome alternative oxidase as a target of chemotherapy. Biochim. Biophys. Acta BBA - Mol. Basis Dis., 1587, 234-239 (2002). 
21. Wolfender, J.-L., Litaudon, M., Touboul, D. \& Queiroz, E. F. Innovative omics-based approaches for prioritisation and targeted isolation of natural products - new strategies for drug discovery. Nat. Prod. Rep., 36, 855-868 (2019).

22. Wang, M. Sharing and community curation of mass spectrometry data with Global Natural Products Social Molecular Networking. Nat. Biotechnol., 34, 828-837 (2016).

23. Noda-Garcia, L. \& Tawfik, D. S. Enzyme evolution in natural products biosynthesis: target- or diversityoriented? Curr. Opin. Chem. Biol., 59, 147-154 (2020).

24. Lu, Y., Wang, Y. \& Zhu, W. Nonbonding interactions of organic halogens in biological systems: implications for drug discovery and biomolecular design. Phys. Chem. Chem. Phys., 12, 4543 (2010).

25. van Dijk, E. L., Jaszczyszyn, Y., Naquin, D. \& Thermes, C. The third revolution in sequencing technology. Trends Genet., 34, 666-681 (2018).

26. Blin, K. et al. antiSMASH 6.0: improving cluster detection and comparison capabilities. Nucleic Acids Res., 49, W29-W35 (2021).

27. Lin, F.-Y. \& MacKerell, A. D. Do halogen-hydrogen bond donor interactions dominate the favorable contribution of halogens to ligand-protein binding? J. Phys. Chem. B, 121, 6813-6821 (2017).

28. Mendez, L., Henriquez, G., Sirimulla, S. \& Narayan, M. Looking back, looking forward at halogen bonding in drug discovery. Molecules, 22, 1397 (2017).

29. Bode, H. B., Bethe, B., Höfs, R. \& Zeeck, A. Big effects from small changes: possible ways to explore nature's chemical diversity. Chembiochem Eur. J. Chem. Biol., 3, 619-627 (2002).

30. Schiewe, H.-J. \& Zeeck, A. Cineromycins, y-butyrolactones and ansamycins by analysis of the secondary metabolite pattern created by a single strain of Strepomyces. J. Antibiot., 52, 635-642 (1999).

31. Brel, O. et al. Paecilosetin derivatives as potent antimicrobial agents from Isaria farinosa. J. Nat. Prod., 83, 2915-2922 (2020).

32. Hoang, T. P. T. et al. Metabolomics-driven discovery of meroterpenoids from a mussel-derived Penicillium ubiquetum. J. Nat. Prod., 81, 2501-2511 (2018).

33. Olivon, F. et al. MetGem software for the generation of molecular networks based on the t-SNE algorithm. Anal. Chem., 90, 13900-13908 (2018).

34. de Laeter, J. R. et al. Atomic weights of the elements. Review 2000 (IUPAC Technical Report). Pure Appl. Chem., 75, 683-800 (2003).

35. Tsugawa, H. et al. MS-DIAL: data-independent MS/MS deconvolution for comprehensive metabolome analysis. Nat. Methods, 12, 523-526 (2015).

36. Horai, H. et al. MassBank: a public repository for sharing mass spectral data for life sciences. J. Mass Spectrom., 45, 703-714 (2010).

37. Fielding, H. C., Robertson, A., Travers, R. B. \& Whalley, W. B. 371. The chemistry of fungi. Part XXXII. The oxidation of sclerotioramine and the structure of sclerotiorin. J. Chem. Soc. Resumed, 18141824 (1957). 
38. Eade, R. A., Page, H., Robertson, A., Turner, K. \& Whalley, W. B. 986. The chemistry of fungi. Part XXVIII. Sclerotiorin and its hydrogenation products. J. Chem. Soc. Resumed, 4913 (1957).

39. Pairet, L., Wrigley, S. K., Reynolds, I. E. \& Hayes, M. A. Taxonomy, fermentation, isolation, structure elucidation and biological activity. J. Antibiot., 48, 913-923 (1995).

40. Araki, Y. et al. Complete biosynthetic pathways of ascofuranone and ascochlorin in Acremonium egyptiacum. Proc. Natl. Acad. Sci. U.S.A., 116, 8269-8274 (2019).

41. Database for chemical compounds, bibliographic data and chemical reactions. https://www-reaxyscom (accessed on November 22, 2021).

42. Pavesi, C. et al. Biosynthesis of azaphilones: a review. Nat. Prod. Rep., 38, 1058-1071 (2021).

43. Sato, M. et al. Combinatorial generation of chemical diversity by redox enzymes in chaetoviridin biosynthesis. Org. Lett., 18, 1446-1449 (2016).

44. Simão, F. A., Waterhouse, R. M., loannidis, P., Kriventseva, E. V. \& Zdobnov, E. M. BUSCO: assessing genome assembly and annotation completeness with single-copy orthologs. Bioinformatics, 31, 3210-3212 (2015).

45. Huang, X., Zhang, W., Tang, S., Wei, S. \& Lu, X. Collaborative biosynthesis of a class of bioactive azaphilones by two separate gene clusters containing four PKS/NRPSs with transcriptional crosstalk in fungi. Angew. Chem. Int. Ed., 59, 4349-4353 (2020).

46. Winter, J. M. et al. Identification and characterization of the chaetoviridin and chaetomugilin gene cluster in Chaetomium globosum reveal dual functions of an iterative highly-reducing polyketide synthase. J. Am. Chem. Soc., 134, 17900-17903 (2012).

47. Chiang, Y.-M. et al. A Gene cluster containing two fungal polyketide synthases encodes the biosynthetic pathway for a polyketide, asperfuranone, in Aspergillus nidulans. J. Am. Chem. Soc., 131, 2965-2970 (2009).

48. Zabala, A. O., Xu, W., Chooi, Y.-H. \& Tang, Y. Characterization of a silent azaphilone gene cluster from Aspergillus niger ATCC 1015 reveals a hydroxylation-mediated pyran-ring formation. Chem. Biol., 19, 1049-1059 (2012).

49. Mori, S., Pang, A. H., Thamban Chandrika, N., Garneau-Tsodikova, S. \& Tsodikov, O. V. Unusual substrate and halide versatility of phenolic halogenase PItM. Nat. Commun., 10, 1255 (2019).

50. Fraley, A. E. et al. Function and structure of MalA/MalA', Iterative halogenases for late-stage $\mathrm{C}-\mathrm{H}$ functionalization of indole alkaloids. J. Am. Chem. Soc., 139, 12060-12068 (2017).

51. Matsuzaki, K. et al. New brominated and halogen-less derivatives and structure-activity relationship of azaphilones inhibiting gp120-CD4 binding. J. Antibiot. (Tokyo), 51, 1004-1011 (1998).

52. Paranjape, S. R. et al. Azaphilones inhibit tau aggregation and dissolve tau aggregates in vitro. ACS Chem. Neurosci., 6, 751-760 (2015).

53. Somoza, A. D., Lee, K.-H., Chiang, Y.-M., Oakley, B. R. \& Wang, C. C. C. Reengineering an azaphilone biosynthesis pathway in Aspergillus nidulans to create lipoxygenase inhibitors. Org. Lett., 14, 972975 (2012). 
54. Frank, M. et al. Brominated azaphilones from the sponge-associated fungus Penicillium canescens Strain 4.14.6a. J. Nat. Prod., 82, 2159-2166 (2019).

55. Chen, M. et al. NaBr-induced production of brominated azaphilones and related tricyclic polyketides by the marine-derived fungus Penicillium janthinellum HK1-6. J. Nat. Prod., 82, 368-374 (2019).

56. Latham, J., Brandenburger, E., Shepherd, S. A., Menon, B. R. K. \& Micklefield, J. Development of Halogenase Enzymes for Use in Synthesis. Chem. Rev., 118, 232-269 (2018).

57. Fauchery, L., Uroz, S., Buée, M. \& Kohler, A. Purification of fungal high molecular weight genomic DNA from environmental samples. in Fungal Genomics, (eds. de Vries, R. P., Tsang, A. \& Grigoriev, I. V.) vol. 1775 21-35 (Springer New York, 2018).

58. De Coster, W., D’Hert, S., Schultz, D. T., Cruts, M. \& Van Broeckhoven, C. NanoPack: visualizing and processing long-read sequencing data. Bioinformatics, 34, 2666-2669 (2018).

59. Di Genova, A., Buena-Atienza, E., Ossowski, S. \& Sagot, M.-F. Efficient hybrid de novo assembly of human genomes with WENGAN. Nat. Biotechnol., 39, 422-430 (2021).

60. Salgado-Salazar, C., Rossman, A.Y., Samuels, G.J. et al. Phylogeny and taxonomic revision of Thelonectria discophora (Ascomycota, Hypocreales, Nectriaceae) species complex. Fungal Diversity 70, 1-29 (2015).

61. Chambers, M. C. et al. A cross-platform toolkit for mass spectrometry and proteomics. Nat. Biotechnol., 30, 918-920 (2012).

62. Pluskal, T., Castillo, S., Villar-Briones, A. \& Orešič, M. MZmine 2: Modular framework for processing, visualizing, and analyzing mass spectrometry-based molecular profile data. BMC Bioinformatics, 11, 395 (2010).

63. Olivon, F., Grelier, G., Roussi, F., Litaudon, M. \& Touboul, D. MZmine 2 Data-Preprocessing To Enhance Molecular Networking Reliability. Anal. Chem. 89, 7836-7840 (2017).

64. European Committee on Antimicrobial Susceptibility Testing: EUCAST. Available online: https://eucast.org/ (accessed on April 11, 2020).

\section{Figures}




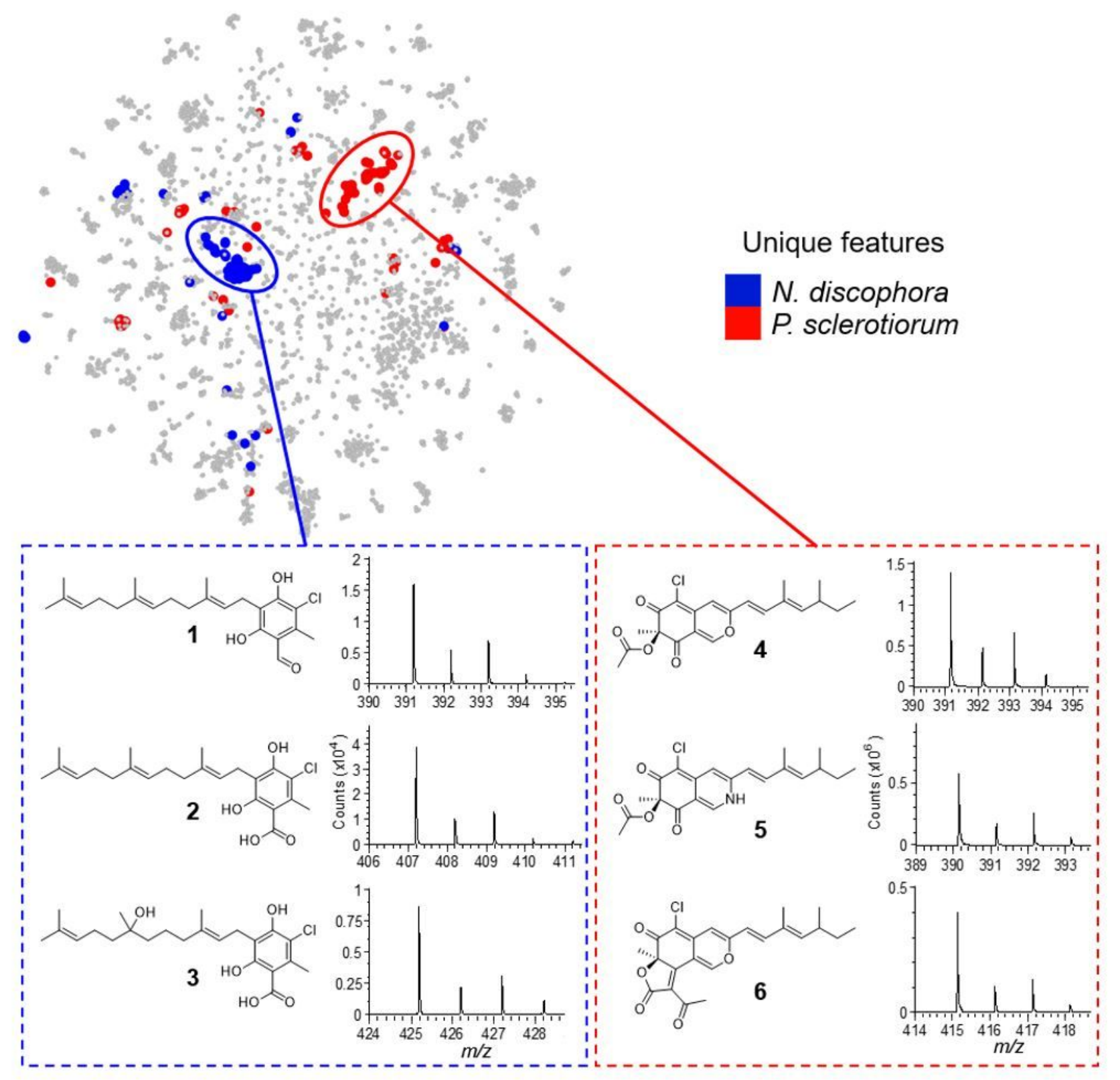

Figure 1

Specific specialized metabolomes of $P$. sclerotiorum and $N$. discophora among 130 crude extracts of termite-associated microorganisms. Chlorinated metabolites annotated by comparison of MS/MS spectrum databases are depicted with their typical isotopic pattern related to ${ }^{37} \mathrm{Cl}$. 
Ndi_lli gene cluster
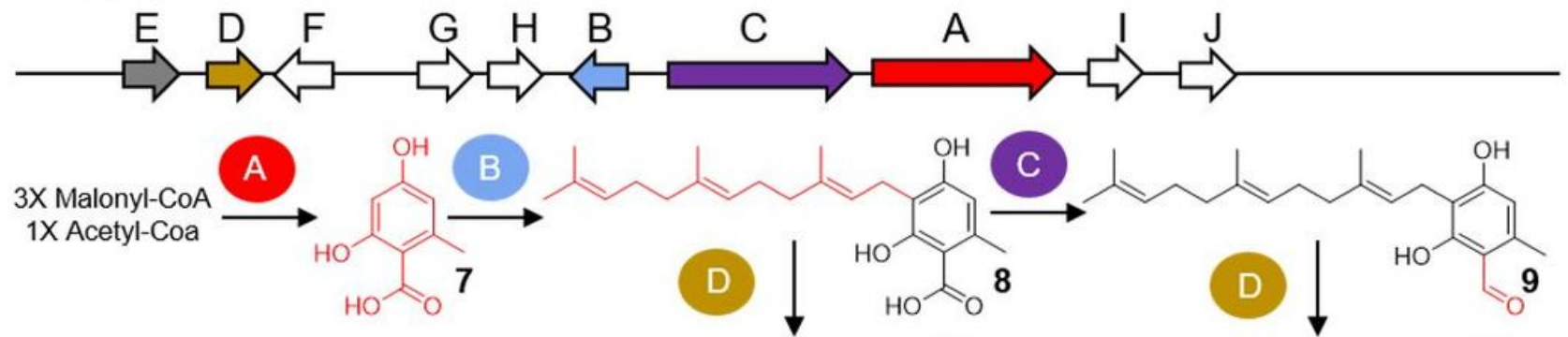

Predicted gene function<smiles>CC(C)=CCC/C(C)=C/CC/C(C)=C/Cc1c(O)c(O)c(Cl)c(C(=O)O)c1C(=O)O</smiles>

\begin{tabular}{|l}
\hline \\
NR-PKS \\
NRPS
\end{tabular}

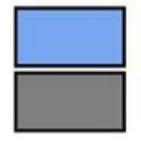

Prenyltransferase

Regulatory and transport

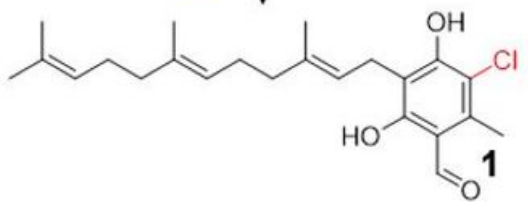

FAD halogenase

Other/ Unknown function

\section{Figure 2}

Annotated biosynthetic gene cluster of $N$. discophora SNB-CN63 and related biosynthetic pathways. NRPKS: non-reducing polyketide synthase, NRPS: non-ribosomal peptide synthase. 


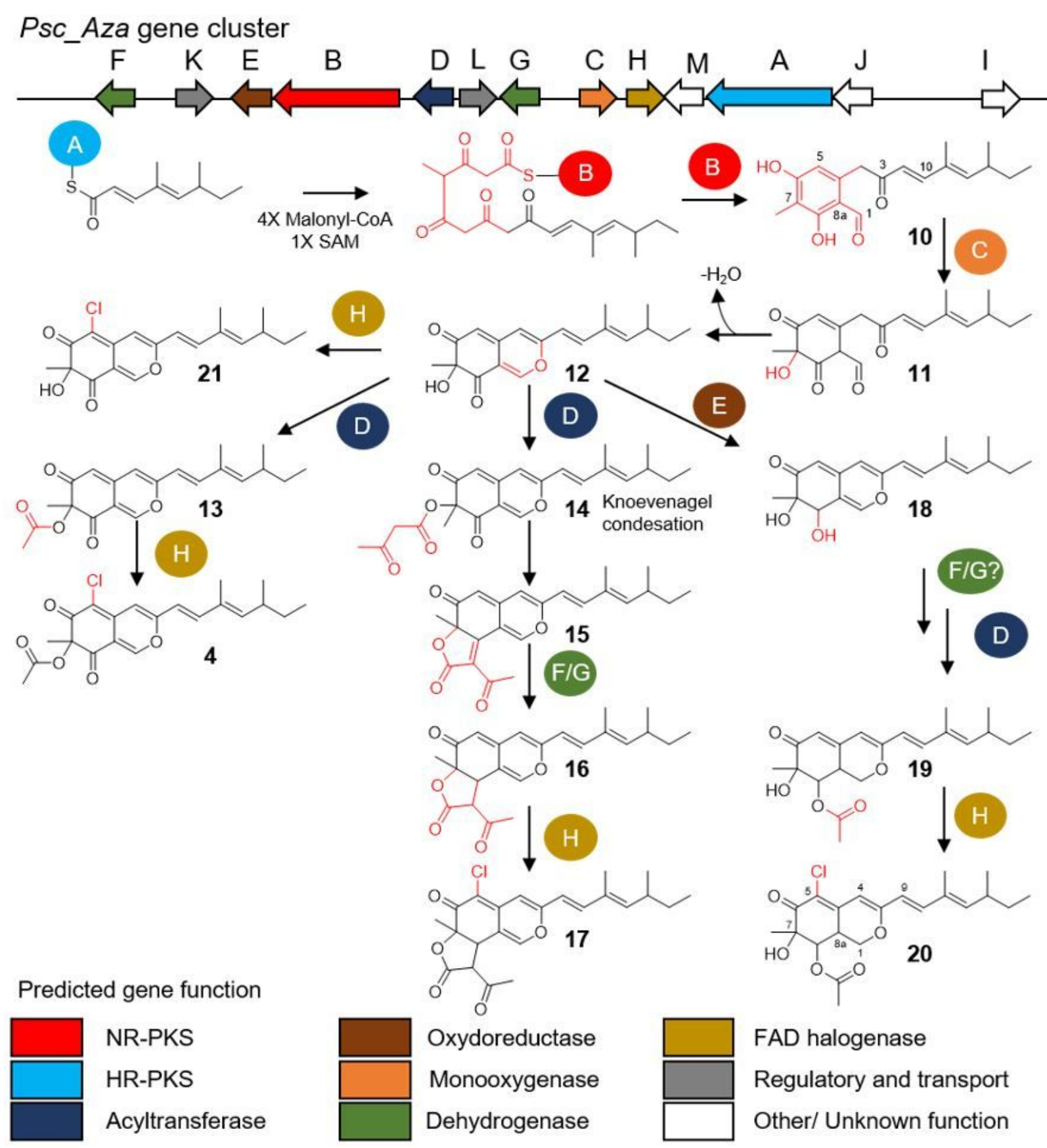

\section{Figure 3}

Annotated biosynthetic gene cluster of $P$. sclerotiorum SNB-CN111 and related biosynthetic pathways. NR-PKS: non-reducing polyketide synthase, HR-PKS: highly reducing polyketide synthase. 

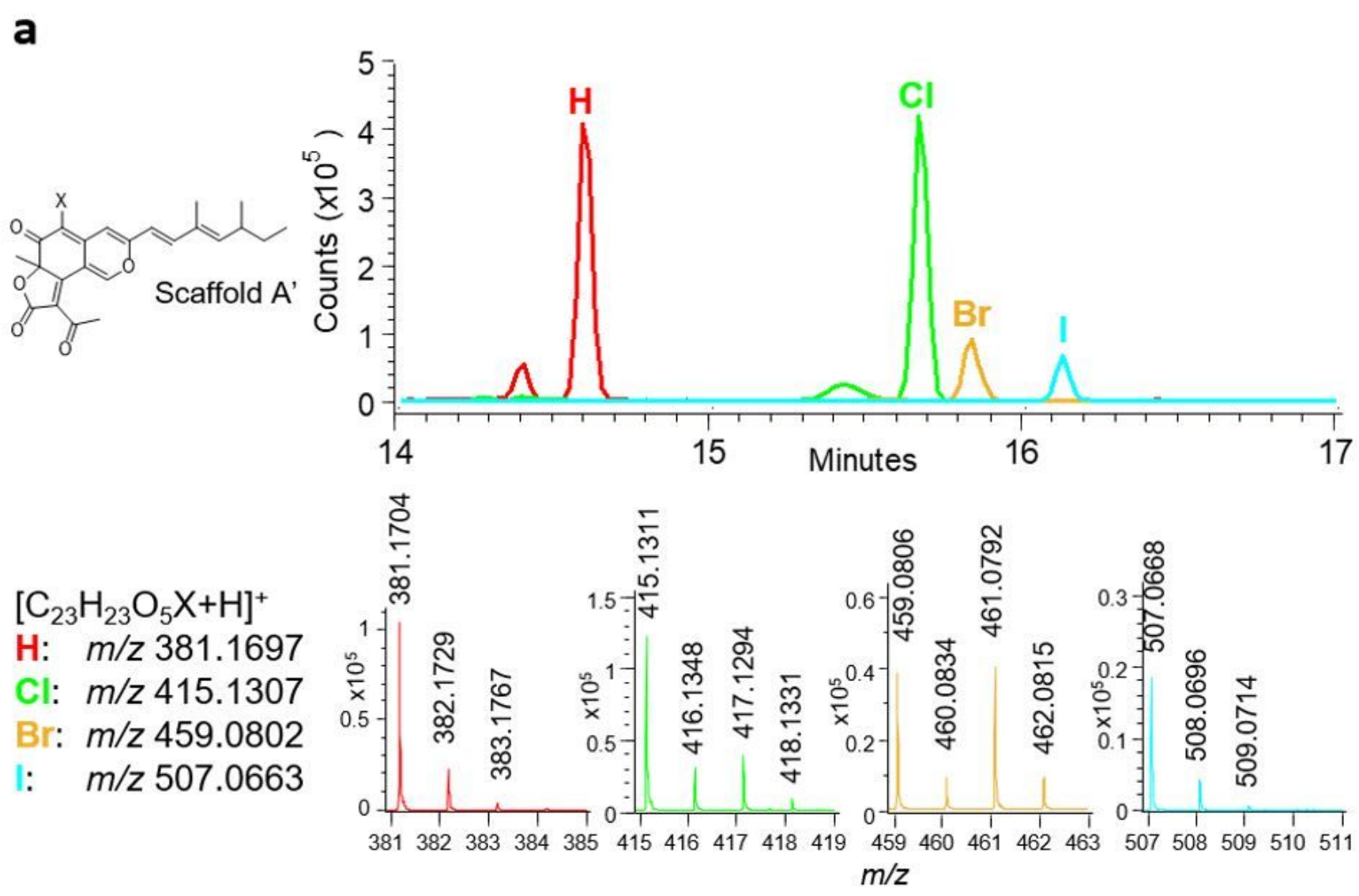

b

X: $\quad \mathrm{H}, \mathrm{Cl}, \mathrm{Br}$
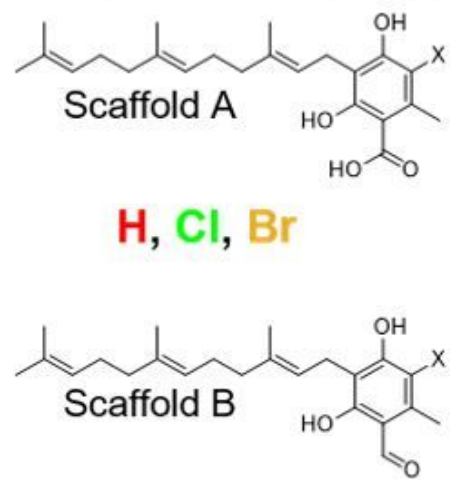

$\mathrm{X}: \quad \mathrm{H}, \mathrm{Cl}, \mathrm{Br}$
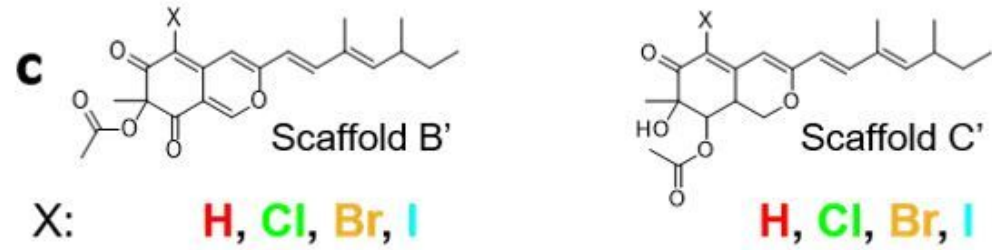

$\mathrm{H}, \mathrm{Cl}, \mathrm{Br}, \mathrm{I}$

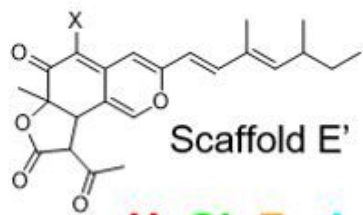

$\mathrm{H}, \mathrm{Cl}, \mathrm{Br}, \mathrm{I}$

\section{Figure 4}

Generation of halogenated azaphilones and ilicolins by OSMAC method. (a) Extracted ion chromatograms of halogenated azaphilones from scaffold $\mathrm{A}^{\prime}(\mathrm{H}, \mathrm{Cl}, \mathrm{Br}$ and $\mathrm{I})$ with their isotopic patterns. (b) Identified halogenations from Ndi_lli_D on ilicicolin scaffolds $A$ and $B$. (c) Identified halogenations from Psc_Aza_H on azaphilone scaffolds B', C', D' and E'. 

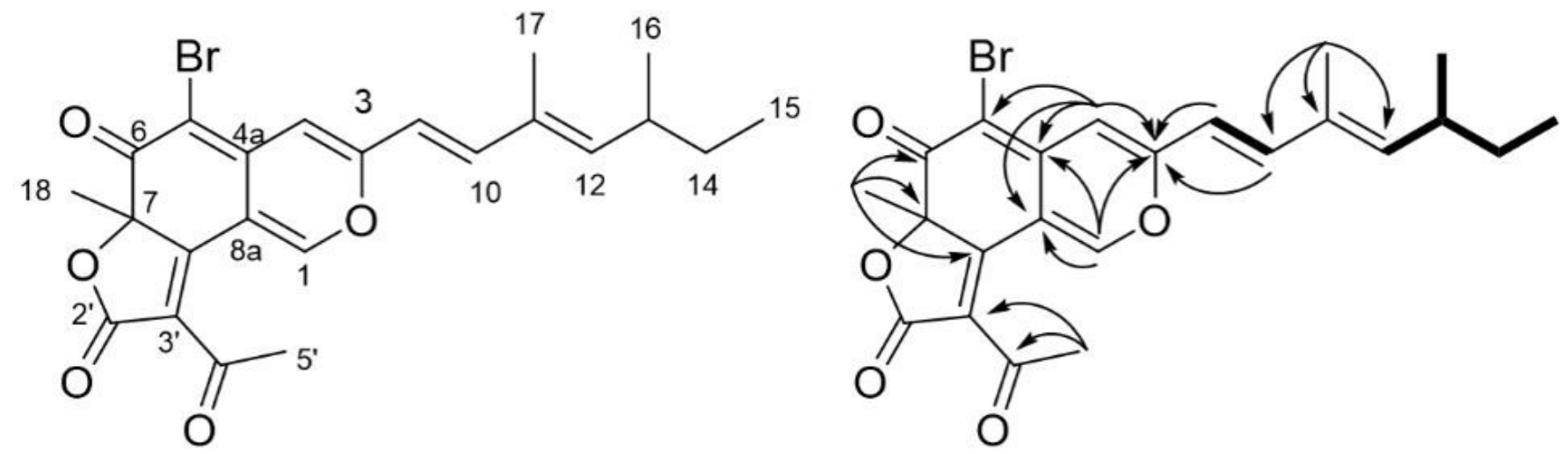

Figure 5

Structural elucidation of compound 22 and 2D RMN correlations observed: ${ }^{1} \mathrm{H}-{ }^{1} \mathrm{H}$ COSY (in bold) and ${ }^{1} \mathrm{H}-$ ${ }^{13} \mathrm{C}$ HMBC (arrows).

\section{Supplementary Files}

This is a list of supplementary files associated with this preprint. Click to download.

- Articlesupptous.pdf

- GA.jpg 